\title{
Rural-urban differences in the prevalence and predictors of depression among adolescents in South Africa
}

\author{
C K Ajaero, ${ }^{1,2} \mathrm{PhD} ; \mathrm{C}$ T Nzeadibe, ${ }^{1} \mathrm{PhD} ;$ E E Igboeli, ${ }^{1} \mathrm{BSc}$ \\ ${ }^{1}$ Department of Geography, Faculty of the Social Sciences, University of Nigeria, Nsukka, Nigeria \\ ${ }^{2}$ Demography and Population Studies, Faculties of Health Sciences and Social Sciences, University of the Witwatersrand, Johannesburg, \\ South Africa
}

Corresponding author: C K Ajaero (chukwuedozie.ajaero@unn.edu.ng)

\begin{abstract}
Background. Mental health is part of overall health, but there is dearth of research on the rural-urban differences of depression among adolescents in South Africa (SA).

Objectives. To present an analysis of rural-urban differences in the prevalence of depression and to assess the sociodemographic predictors of depression among adolescents in SA.

Methods. Data were obtained from the National Income Dynamics Study (NIDS), wave 4 of 2014, which was conducted on a nationally representative sample of 3751 respondents (15 - 19 years). Univariate analysis was used to describe the study population while bivariate analysis was used to test for significant differences in the depression status of the population. Finally, binary logistic regression was used to estimate the predictors of depression.

Results. Urban adolescents (14.64\%) were more depressed than their rural counterparts (9.40\%). Gender, income levels and province of residence also showed significant differences in both rural and urban areas. The significant predictors of depression in both rural and urban areas were race, age, income and province of residence.

Conclusion. Counselling and rehabilitation programmes should be targeted more at urban, more educated and higher-earning adolescents, especially in provinces with a relatively higher prevalence of depression.
\end{abstract}

S Afr J Child Health 2018;12(2 Suppl 1):S71-S74. DOI:10.7196/SAJCH.2018.v12i2.1509

Globally, mental health problems contribute considerably to disability-adjusted life years and may be prevalent in about a quarter of young people. ${ }^{[1,2]}$ In South Africa (SA), the adjusted prevalence of mental illnesses of adolescents in the Western Cape is estimated at $15-17 \% \cdot{ }^{[3]}$ Also, the nationally representative South African Stress and Health (SASH) study showed that approximately $20 \%$ of youth in SA suffer from depression and stress-related conditions every year. ${ }^{[4,5]}$ However, there remains a dearth of evidence on the rural-urban differences in prevalence and predictors of depression among adolescents in SA.

Adolescents undergo various biological, cognitive, physiological, psychological, emotional and social changes. These changes affect their health and wellbeing. ${ }^{[6,7]}$ As such, it has been noted that mental problems are more likely to develop during adolescence ${ }^{[8]}$ Generally, mental illnesses account for $45 \%$ of the burden of disease in people aged 10 - 24 years old, ${ }^{[7,9]}$ with depression and anxiety noted as the leading causes of mental disorders. ${ }^{[2,10]}$ Studies have also suggested that these disorders affect economic and educational outcomes and contribute to crime and suicide rates of adolescents. ${ }^{[2,10]}$ Furthermore, research shows that female gender, ${ }^{[1,12]}$ a low level of education, ${ }^{[13,14]}$ higher age, ${ }^{[15,16]}$ a lower socioeconomic status, ${ }^{[17,18]}$ rural residency ${ }^{[19]}$ and living in urban neighbourhoods ${ }^{[20]}$ are associated with a higher prevalence of depression. In addition, racially advantaged population groups in any area appear to have a lower prevalence of depression, ${ }^{[21]}$ while people's geographical location has also been shown to affect their depression status. ${ }^{[2,22]}$

As mental health problems that develop during adolescence usually persist into adulthood, the prevalence of depression in adolescence remains a strong predictor for mental health problems in adulthood. ${ }^{[1,7]}$ This means that mental health problems in lowand middle-income countries, including SA, must be addressed effectively to ensure optimal development of human capital for the future. ${ }^{[23]}$ As such, the prevalence and predictors of depression among adolescents need to be assessed. This study examines the rural-urban differences in prevalence and predictors of depression among adolescents in SA.

\section{Methods}

The study used data from the 2014 National Income Dynamics Study (NIDS), which was a survey of individuals and households across the nine provinces of SA. Data for adolescents aged 15 - 19 years were extracted from the survey results and used for this study.

Depression status of respondents, used as the dependent variable, was derived from responses to the 10-item Center for Epidemiological Studies Depression scale questionnaire (CES-D 10). The CES-D scale has been validated as a reliable measure of depression for the SA context based on NIDS data. ${ }^{[24]}$ The 10 questions assess whether, in the week preceding the survey, certain feelings occurred: (i) rarely or none of the time; (ii) some or little of the time; (iii) occasionally or a moderate amount of time; or (iv) all of the time. Responses were then scored from ' 0 ' (rarely or none of the time) to ' 3 ' (all of the time). The exception to this scoring were questions 5 and 8 ('I feel hopeful about the future' and 'I was happy', respectively), which were reverse coded on the Likert scale. Individual scores for each item were added up to calculate the overall depression score. Based on the scoring specification of the CES-D 10 scale, these scores were then expressed in terms of a a dichotomous variable, with 'depressed' 
assigned a value of 1 and 'not depressed' assigned a value of 0 . In categorising the depression status, scores of $>10$ were regarded as 'depressed', while values $\leq 10$ were regarded as 'not depressed'. The term 'depression status' as used in this study connotes measures of psychological distress (symptoms of depression and anxiety) and not necessarily the presence or absence of psychiatric disorders. ${ }^{[21,25]}$ The independent variables used in this study were: age (15 - 19 years); gender (male/female); education (primary/ post primary); race (black African/non-black); individual income (<ZAR1 000/ZAR1 000 - R10 000/>ZAR10 000), and province of residence (any of the nine SA provinces).

Before data analysis, the dataset was weighted to account for differences due to under- or oversampling errors. All the analyses were performed on the basis of rural-urban differences. Univariate analysis was used to describe the study population, while bivariate analysis was used to test for significant differences in the depression status of the study population. Finally, binary logistic regression analysis was used to predict the factors of depression in the population. Following Steffick, ${ }^{[25]}$ the model is described as:

$y=\alpha+\beta_{0}+\beta_{1} x_{1}+\beta_{2} x_{2}+\beta_{3} x_{3}+\beta_{\mathrm{n}} x_{\mathrm{n}}+\varepsilon_{\mathrm{i}}$

where $y$ represents the dichotomous dependent variable (depression status), $\alpha$ is the gradient, $\beta$ is the coefficients, $x$ represents independent variables (such as age, education and province of residence) and $\varepsilon_{\mathrm{i}}$ is the error term, with a confidence level of $95 \%$ and a $5 \%$ allowance for error. The coefficients indicate the likelihood for a respondent being depressed or not, with a value of $>1.00$ indicating a depressed status and a value of $<1.00$ indicating a status of not being depressed. This study has a regression model for each of the respective geographical areas: model 1 for rural areas and model 2 for urban areas.

\section{Results}

\section{Demographic characteristics of the study population}

Slightly more rural adolescents participated in the survey than urban adolescents (Table 1). Black Africans made up $96.40 \%$ and $73.88 \%$ of the populations in the rural and urban areas, respectively. The proportions of respondents with post primary education were $85 \%$ and $86.12 \%$ in rural and urban areas, respectively.

\section{Prevalence of depression}

The bivariate analysis revealed a significant difference in the prevalence of depression between rural and urban respondents (Table 2). In rural areas, $9.40 \%$ of adolescents were depressed compared with a prevalence of $14.64 \%$ among urban adolescents. In addition, the results showed significant differences in the prevalence of depression between racial groups, income ranges, and provincial distribution in both rural and urban areas. For example, while 25\% of rural adolescents in Gauteng were depressed, only $4.76 \%$ of rural adolescents in the Free State reported being depressed. In contrast, $23.03 \%$ and $3.85 \%$ of urban adolescents were depressed in the Western Cape and Limpopo provinces, respectively.

\section{Predictors of depression}

The significant predictors of depression status among adolescents in both rural and urban areas were age, race, income and province of residence (Table 3). According to model 1 (rural area), the factors that significantly increased the likelihood of depression were: increasing age (odds ratio (OR) 1.176; $p=0.05$ ) and having an income of ZAR1 000 - ZAR10 000 (OR 1.653; $p=0.05$ ). In the urban areas (model 2), a significant likelihood of depression was found among respondents from all provinces except the Western Cape, and for increasing age (OR 1.266; $p=0.001)$, non-black respondents (OR 2.204; $p=0.001)$ and those with an income range of ZAR1 000 - ZAR10 000 (OR 2.025; $p=0.001)$.
Table 1. Demographic characteristics of the study population

\begin{tabular}{|c|c|c|}
\hline Variables & Rural, $n(\%)$ & Urban, $n(\%)$ \\
\hline \multicolumn{3}{|l|}{ Age (years) } \\
\hline 15 & $383(17.91)$ & $308(19.11)$ \\
\hline 16 & $446(20.85)$ & $324(20.09)$ \\
\hline 17 & $413(19.31)$ & 377 (23.39) \\
\hline 18 & $451(21.08)$ & $299(18.55)$ \\
\hline 19 & $446(20.85)$ & $304(18.86)$ \\
\hline \multicolumn{3}{|l|}{ Gender } \\
\hline Male & $1055(49.32)$ & $774(48.01)$ \\
\hline Female & $1084(50.68)$ & $838(51.99)$ \\
\hline \multicolumn{3}{|l|}{ Race } \\
\hline Black African & $2062(96.40)$ & $1191(73.88)$ \\
\hline Non-black & $76(3.60)$ & $421(26.12)$ \\
\hline \multicolumn{3}{|l|}{ Education } \\
\hline Primary & $320(15.00)$ & $224(13.90)$ \\
\hline Post primary & $1813(85.00)$ & $\begin{array}{l}1387(86.10) \\
161116\end{array}$ \\
\hline \multicolumn{3}{|l|}{ Income (ZAR) } \\
\hline$<1000$ & $1005(48.20)$ & $573(37.16)$ \\
\hline $1000-10000$ & $903(43.31)$ & $746(48.38)$ \\
\hline$>10000$ & 177 (8.49) & $223(14.46)$ \\
\hline \multicolumn{3}{|l|}{ Province } \\
\hline Western Cape & $33(2.12)$ & $152(14.29)$ \\
\hline Eastern Cape & $190(12.18)$ & $156(14.66)$ \\
\hline Northern Cape & $30(1.91)$ & $138(12.97)$ \\
\hline Free State & $21(1.35)$ & $125(11.74)$ \\
\hline KwaZulu-Natal & $805(51.60)$ & $168(15.79)$ \\
\hline North West & $94(6.02)$ & $70(6.58)$ \\
\hline Gauteng & $16(1.03)$ & $152(14.29)$ \\
\hline Mpumalanga & $121(7.76)$ & $77(7.24)$ \\
\hline Limpopo & $250(16.03)$ & $26(2.44)$ \\
\hline Total & $2139(50.02)$ & $1612(49.98)$ \\
\hline
\end{tabular}

\section{Discussion}

Generally, the likelihood of depression varied significantly between respondents from rural and urban areas. Depression status also varied significantly between provinces, gender, and income and racial groups within the rural and urban areas. The higher prevalence of depression in urban areas may be due to the more complex and stressful nature of urban living.

The results agree with various earlier studies that reported geographical characteristics such as rural or urban residence to affect depression status. ${ }^{[19-21]}$ The higher likelihood of depression associated with increasing age in both rural and urban areas agree with previous research that averred higher age to be associated with a higher prevalence of depression. ${ }^{[16]}$ This may be related to adolescents' being burdened with seemingly overwhelming tasks, both at home and at school, or they may experience failures, which could leading to feelings of depression. In both models, a lower prevalence of depression was associated with female respondents. This is contrary to findings from studies that suggested that women experience a higher prevalence of depression than men. ${ }^{[1,12]}$ This contradiction may be a result of male adolescents being involved in tedious or artisan work more often, which may affect their depression status. 
Table 2. Bivariate analysis of the prevalence of depression

\begin{tabular}{|c|c|c|c|c|}
\hline \multirow[b]{2}{*}{ Variables } & \multicolumn{2}{|c|}{ Rural } & \multicolumn{2}{|c|}{ Urban } \\
\hline & $n(\%)$ & $x^{2}$ & $n(\%)$ & $\chi^{2}$ \\
\hline Age (years) & & 8.93 & & 8.66 \\
\hline 15 & $48(12.53)$ & & $58(18.83)$ & \\
\hline 16 & 39 (8.74) & & $53(16.36)$ & \\
\hline 17 & $42(10.17)$ & & $48(12.73)$ & \\
\hline 18 & $30(6.65)$ & & $42(14.05)$ & \\
\hline 19 & $42(9.42)$ & & $35(11.51)$ & \\
\hline Gender & & 0.37 & & 0.37 \\
\hline Male & $89(8.44)$ & & $109(14.08)$ & \\
\hline Female & $112(10.33)$ & & $127(15.16)$ & \\
\hline Race & & $15.09^{\ddagger}$ & & $5.51^{\star}$ \\
\hline Black African & $184(8.92)$ & & $189(15.87)$ & \\
\hline Non-black & $11(22.08)$ & & 47 (11.16) & \\
\hline Education & & 1.47 & & 0.22 \\
\hline Primary & $36(11.25)$ & & $35(15.63)$ & \\
\hline Post primary & $165(9.10)$ & & $200(14.42)$ & \\
\hline Income (ZAR) & & $68.10^{\ddagger}$ & & $34.51^{\ddagger}$ \\
\hline$<1000$ & $97(9.65)$ & & $103(17.98)$ & \\
\hline $1000-10000$ & $52(5.76)$ & & $72(9.65)$ & \\
\hline >ZAR10 000 & $45(25.42)$ & & $53(23.77)$ & \\
\hline Province & & $20.72^{\dagger}$ & & $30.31^{\ddagger}$ \\
\hline Western Cape & $3(9.09)$ & & $35(23.03)$ & \\
\hline Eastern Cape & $28(14.74)$ & & $27(17.31)$ & \\
\hline Northern Cape & $4(13.33)$ & & $7(5.07)$ & \\
\hline Free State & $1(4.76)$ & & $15(12.00)$ & \\
\hline KwaZulu-Natal & $54(6.71)$ & & $15(8.93)$ & \\
\hline North West & $7(7.45)$ & & $13(18.57)$ & \\
\hline Gauteng & $4(25.00)$ & & $25(16.45)$ & \\
\hline Mpumalanga & $14(1157)$ & & $8(10.39)$ & \\
\hline Limpopo & $26(10.40)$ & & $1(3.85)$ & \\
\hline Total & $201(9.40)$ & & $236(14.64)$ & $24.55^{\ddagger}$ \\
\hline $\begin{array}{l}{ }^{*} p<0.05 . \\
{ }^{t} p<0.01 . \\
{ }^{*} p<0.001 .\end{array}$ & & & & \\
\hline
\end{tabular}

Results from our study show that higher income was associated with an increased likelihood for depression. This contradicts earlier studies, which posited that people with a lower socioeconomic status tend to be more prone to depression. ${ }^{[17,18]}$ The reason for adolescents with higher incomes to be more depressed may be linked to disillusionment resulting from not being able to keep up with increased responsibilities associated with earning more.

Among non-black respondents, a lower likelihood for depression was found for those in rural areas, but a higher likelihood for those in urban areas. These results agree to some extent with those from another study, which posited that racially disadvantaged groups (referring to black South Africans in this context) exhibit a higher prevalence of depression compared with racially advantaged (nonblack) groups; ${ }^{[21]}$ however, the finding that non-black respondents from urban areas have a higher likelihood for depression is contrasting. The higher likelihood for depression among urban non-black respondents may be a result of a greater population of non-blacks being interviewed in urban areas. It is possible that many may be immigrants and that settling in urban areas, where they could be involved in illegitimate activities, could affect their depression status. The results also indicate that adolescents with a higher educational attainment in both the rural and urban areas
Table 3. Logistic regression of predictors of depression

\begin{tabular}{lll}
\hline Variables & Model 1 (Rural) & Model 2 (Urban) \\
\hline Age (continuous) & $1.176^{\star}$ & $1.266^{\ddagger}$ \\
Gender & & \\
Male & 1.000 & 1.000 \\
Female & 0.845 & 0.931 \\
Race & & \\
Black African & 1.000 & 1.000 \\
Non-black & $0.061^{\ddagger}$ & $2.204^{\dagger}$ \\
Education & & \\
Primary & 1.000 & 1.000 \\
Post primary & 1.403 & 1.387 \\
Income (ZAR) & & \\
$<1$ 000 & 1.000 & 1.000 \\
1 000 - 10 000 & $1.653^{\star}$ & $2.025^{\ddagger}$ \\
$>10$ 000 & $0.275^{\ddagger}$ & 0.788 \\
Province & & \\
Western Cape & 1.000 & 1.000 \\
Eastern Cape & $0.039^{\ddagger}$ & $2.658^{\dagger}$ \\
Northern Cape & $0.094^{\star}$ & $6.729^{\ddagger}$ \\
Free State & 0.000 & $4.750^{\ddagger}$ \\
KwaZulu-Natal & $0.103^{\dagger}$ & $6.031^{\ddagger}$ \\
North West & $0.127^{\star}$ & $2.858^{\star}$ \\
Gauteng & $0.030^{\dagger}$ & $3.177^{\dagger}$ \\
Mpumalanga & $0.074^{\dagger}$ & $5.183^{\dagger}$ \\
Limpopo & $0.057^{\dagger}$ & $15.76^{\star}$ \\
${ }^{*}<<0.05$. & & \\
$\dagger_{p}^{\dagger}<0.01$. & & \\
$\ddagger_{p}<0.001$. & & \\
& &
\end{tabular}

reported being more depressed than their counterparts with lower levels of education. ${ }^{[14]}$ This contradiction may stem from increased academic pressure experienced as adolescents progress through the educational system, which may cause stress. With regard to rural/ urban place of residence, the results from all the analyses show that residing in an urban area increases the likelihood of being depressed. This findings is in line with the view of an earlier study. ${ }^{[20]}$

\section{Conclusion}

This study has shown that the prevalence of depression among adolescents in SA varies significantly between rural and urban populations. Increase in income, province of residence and increasing age were associated with higher likelihoods of depression in the study population. Regular counselling and rehabilitation programmes are recommended for adolescents, specifically in provinces with a relatively higher prevalence of depression, with a specific focus on those in urban areas, older adolescents and higher-income earners.

Acknowledgements. The support of the DST-NRF Centre of Excellence (CoE) in Human Development for this research is hereby acknowledged. Opinions expressed and conclusions arrived at are those of the authors, and are not necessarily to be attributed to the CoE in Human Development. Thee authors gratefully acknowledge the support of the Demography and Population Studies Programme, Schools of Public Health and Social Sciences, Faculties of Health Sciences and Humanities, University of the Witwatersrand, Johannesburg, South Africa.

Author contributions. CKA conceptualised the study and designed and drafted the manuscript together with CTN. CKA and EEI were 
responsible for data analysis and mapping of the results. All the authors reviewed and approved the final draft of the manuscript.

Funding. None.

Conflicts of interest. None.

1. Belfer ML. Child and adolescent mental disorders: The magnitude of the problem across the globe. J Child Psychol Psychiatry 2008;49(3):226-236. https://doi.org/10.1111/j.1469-7610.2007.01855.x

2. Patel V. Why adolescent depression is a global health priority and what we should do about it. J Adolesc Health 2013;52(5):511-512. https://doi. org/10.1016/j.jadohealth.2013.03.003

3. Kleintjes S, Flisher A, Fick M, et al. The prevalence of mental disorders among children, adolescents and adults in the Western Cape, South Africa. S Afr Psychiatry Rev 2006;9(3):157-160. https://doi.org/10.4314/ajpsy.v9i3.30217

4. Tomlinson M, Grimsrud AT, Stein DJ, Williams DR, Myer L. The epidemiology of major depression in South Africa: Results from the South African Stress and Health study. S Afr Med J 2009;99(5 Pt 2):367-373.

5. Herman AA, Stein DJ, Seedat S, Heeringa SG, Moomal H, Williams DR. The South African Stress and Health (SASH) study: 12-month and lifetime prevalence of common mental disorders. S Afr Med J 2009;99(5 Pt 2):339-344.

6. Sawyer SM, Afifi RA, Bearinger LH, et al. Adolescence: A foundation for future health. Lancet 2012;379:1630-1640. https://doi.org/10.1016/s01406736(12)60072-5

7. Abou Abbas O, AlBuhairan F. Predictors of adolescents' mental health problems in Saudi Arabia: Findings from the Jeeluna national study. Child Adolesc Psychiatry Ment Health 2017;11:52. https://doi.org/10.1016/j. jadohealth.2017.11.108

8. World Health Organization. Risks to mental health: an overview of vulnerabilities and risk factors. Geneva: WHO, 2012.

9. Gore FM, Bloem PJN, Patton GC, et al. Global burden of disease in young people aged 10-24 years: A systematic analysis. Lancet 2011;377(9783):20932102. https://doi.org/10.1016/s0140-6736(11)60512-6

10. Das-Munshi J, Lund C, Mathews C, Clark C, Rothon C, Stansfeld S. Mental health inequalities in adolescents growing up in post-apartheid South Africa: Cross-sectional survey, SHaW study. PLoS ONE 2016;11(5):e0154478. https://doi.org/10.1371/journal.pone.0154478

11. Watson KT, Roberts NM, Saunders MR. Factors associated with anxiety and depression among African American and White women. ISRN Psychiatry 2012;2012:432321. https://doi.org/10.5402/2012/432321

12. Mundt A, Kliewe T, Yayla S, et al. Social characteristics of psychological distress in disadvantaged areas of Berlin. Int J Soc Psychiatry 2014;60(1):7582. https://doi.org/10.1177/0020764012464017

13. Batistoni SS, Neri AL, Cupertino AP. Prospective measures of depressive symptoms in community-dwelling elderly individuals. Rev Saúde Pública 2010;44(6):1137-1143.
14. Van der Waerden JEB, Hoefnagels C, Hosman CMH, Jansen MWJ. Defining subgroups of low socioeconomic status women at risk for depressive symptoms: The importance of perceived stress and cumulative risks. Int J Soc Psychiatry 2014;60(8):772-782. https://doi.org/10.1177/0020764014522751

15. Dong X, Chen R, Li C, Simon MA. Understanding depressive symptoms among community-dwelling Chinese older adults in the greater Chicago area. J Aging Health 2014;26(7):1155-1171. https://doi.org/10.1177/0898264314527611

16. Silva M, Loureiro A, Cardoso G. Social determinants of mental health: A review of the evidence. Eur J Psychiat 2016;30(4):259-292

17. Oshio T, Umeda $\mathrm{M}$, Kawakami N. Impact of interpersonal adversity in childhood on adult mental health: How much is mediated by social support and socio-economic status in Japan? Public Health 2013;127(8):754-760. https://doi.org/10.1016/j.puhe.2013.05.005

18. Meyer OL, Castro-Schilo L, Aguilar-Gaxiola S. Determinants of mental health and self-rated health: A model of socioeconomic status, neighborhood safety, and physical activity. Am J Public Health 2014;104(9):1734-1741. https://doi. org/10.2105/ajph.2014.302003

19. Wang Z, Shu D, Dong B, Luo L, Hao Q. Anxiety disorders and its risk factors among the Sichuan empty-nest older adults: A cross-sectional study. Arch Gerontol Geriatr 2013;56(2):298-302. https://doi.org/10.1016/j. archger2012.08.016 20. Mullings JA, McCaw-Binns AM, Archer C, Wilks R. Gender differences in the effects of urban neighborhood on depressive symptoms in Jamaica. Rev Panam Salud Publica 2013;34(6):385-392.

20. Ajaero CK, Odimegwu CO, Chisumpa V, Obisie-Nmehielle N. The influence of internal migration on mental health status in South Africa. Int J Ment Health Promot 2017;19(4):189-201 https://doi.org/10.1080/14623730.2017. 1327879

21. Fone D, Greene G, Farewell D, White J, Kelly M, Dunstan F. Common mental disorders, neighbourhood income inequality and income deprivation: Smallarea multilevel analysis. Br J Psychiatry 2013;202(4):286-293. https://doi. org/10.1192/bjp.bp.112.116178

22. Davidson LL, Grigorenko EL, Boivin MJ, Rapa E, Stein A. A focus on adolescence to reduce neurological, mental health and substance-use disability. Nature 2015;527:S161-S166. https://doi.org/10.1038/nature16030

23. Baron EC, Davies T, Lund C. Validation of the 10-item Centre for Epidemiological Studies Depression Scale (CES-D-10) in Zulu, Xhosa and Afrikaans populations in South Africa. BMC Psychiatry 2017;17:6. https:// doi.org/10.1186/s12888-016-1178-x

24. Steffick DE. Documentation of affective functioning measures in the health and retirement study. Documentation Report DR-005, Survey Research Center at the Institute for Social Research. Ann Arbor: University of Michigan, 2000.

Accepted 19 June 2018 